\section{Aleitamento materno: como é vivenciado por mulheres assistidas em uma unidade de saúde de referência na atenção materno- infantil em Teresina, Piauí}

\author{
Breast-feeding: the way it is experienced by \\ women assisted at a Pediatrics and \\ Maternity Hospital in Teresina in the State \\ of Piauí
}

Carmen Viana Ramos 1

João Aprígio Guerra de Almeida 2

1 Secretaria de Saúde do Estado do Piauí. Av. Pedro Freitas s.n. Centro Administrativo. Teresina, PI, Brasil. CEP: 64018-000. Fones / Fax: (86) 218-1899/ 2110565.

2 Banco de Leite Humano. Instituto Fernandes Figueira. Fundação Oswaldo Cruz.

\begin{abstract}
Objectives: increase the understanding on how women who have weaned their children before the fourth month of life view breast-feeding and care received during the pregnancy and puerperal cycle.

Methods: the theory of Social Representation was used as a theoretical and methodological reference. In the whole 24 women were interviewed through a semi-structured questionnaire. Data analysis was performed based on a content analysis method.

Results: statements analysis of the respondents determined the gap between the standing of the institution favoring exclusive breast-feeding until the sixth month of life and the experience of women related to breast-feeding which established the impossibility of following such recommendation in the face of real life conditions.

Conclusions: results revealed the need of an urgent reformulation of healthcare actions concerning the issue with the objective of considering not only biologic factors but social and cultural conditions involving breastfeeding as well.
\end{abstract}

Key words Breast feeding, Weaning, Pregnancy

\section{Resumo}

Objetivos: ampliar a compreensão acerca de como as mulheres que desmamaram os seus filhos antes do quarto mês de vida percebem a amamentação e a assistência recebida no curso do ciclo gravídicopuerperal.

Métodos: adotou-se a Teoria das Representações Sociais como referencial teórico-metodológico. Ao todo foram entrevistadas 24 mulheres com base num questionário semi-estruturado. A análise dos dados se deu a partir do método de análise de conteúdo.

Resultados: a análise do discurso das entrevistadas permitiu evidenciar um verdadeiro descompasso entre o discurso proferido pela instituição, em favor da amamentação exclusiva até o sexto mês de vida, e a vivência das mulheres com relação a este ato, que se traduziu na impossibilidade de cumprir tal orientação frente as suas condições concretas de vida.

Conclusões: os resultados revelaram a necessidade de uma urgente reformulação nos referenciais que embasam as ações de saúde voltadas para essa área, com vistas a contemplar, além dos determinantes biológicos, os condicionantes socioculturais que permeiam a amamentação.

Palavras-chave Aleitamento materno, Desmame, Gravidez 


\section{Introdução}

A amamentação se transformou em um dos principais objetos de preocupação para os formuladores de políticas públicas em favor da saúde da criança, nacional e internacionalmente em particular após a edição de "The baby killer"na década de 70. ${ }^{1}$ Desde então, inúmeras estratégias foram elaboradas e implementadas em diferentes regiões do globo, inclusive no Brasil, com o objetivo de contribuir para a redução dos índices de morbi-mortalidade infantil através do combate do desmame precoce.

Dentre as formulações da Organização Mundial da Saúde (OMS) e o Fundo das Nações Unidas para a Infância (UNICEF), ${ }^{2}$ figura a hipótese de que um dos mais importantes elementos para o declínio da amamentação, nas duas últimas décadas, foi a adoção de rotinas hospitalares inadequadas. Seguindo essa perspectiva, a maioria das maternidades adota procedimentos que impedem a aproximação mãe e filho no puerpério imediato, além de favorecer o uso de chupetas, mamadeiras e fórmulas lácteas nas práticas hospitalares. 3

Com base nesses referenciais, foi lançado, em 1991, o Programa Iniciativa Hospital Amigo da Criança (IHAC), a ser implantado em todos os países signatários da Declaração de Innocenti. ${ }^{4}$ Essa proposta, operacionalizada através da readequação das rotinas hospitalares em observação ao cumprimento de 10 normas básicas, traz como diferencial, em relação as propostas anteriores para a área, a preocupação em prestar apoio à mulher que amamenta e de protegê-la dos condicionantes sociais que falam em favor do desmame, a exemplo das estratégias de marketing dos fabricantes de fórmulas lácteas. 5

A IHAC vem sendo trabalhada no Brasil desde 1992, sob a responsabilidade do Ministério da Saúde e com o apoio do UNICEF. A proposta inclui ações voltadas para a adoção das leis que protejam o trabalho da mulher lactante e a implementação das normas de comercialização de alimentos para lactentes. ${ }^{6}$

O país dispõe atualmente de 271 Hospitais Amigos da Criança. ${ }^{7}$ No Piauí existem sete unidades hospitalares detentoras desse título, sendo a Maternidade Dona Evangelina Rosa (MDER), a pioneira no estado.

A MDER iniciou o processo de implantação da IHAC em 1993, mas somente em 1997 conseguiu cumprir todos os pré-requisitos exigidos, readequando as suas rotinas de acordo com as exigências do programa. Contudo, apesar de todo o esforço empreendido, verificou-se a existência de mães que abandonam a amamentação exclusiva antes dos quatro meses de vida do filho, contrariando assim a ori- entação dada na instituição. Em termos objetivos, no período de fevereiro a maio de 2000 , essa tendência foi observada em $64 \%$ das mulheres atendidas no Consultório de Acompanhamento Nutricional (CAN) da maternidade.

Como explicar este desvio comportamental da mulher em relação a amamentação? A necessidade de responder essa questão a partir da fala das mulheres se configurou como objetivo desse estudo, que foi desenvolvido no intuito de compreender como as mulheres percebem a assistência no ciclo gravídicopuerperal tendo como eixo central a amamentação.

\section{Métodos}

Optou-se por um estudo de caráter exploratório, ancorado nos preceitos da pesquisa qualitativa em saúde. Esse tipo de pesquisa trabalha com o "... universo de aspirações, crenças, valores e atitude que não podem ser expressos através de variáveis matemáticas" (Minayo; 1994: 21-2). 8 Para tanto, utilizou-se a teoria das representações sociais como referencial metodológico. Segundo Minayo (1994: 89), 9 "... as representações sociais se manifestam em palavras, sentimentos e condutas e se institucionalizam, portanto, podem e devem ser analisadas a partir da compreensão das estruturas e dos comportamentos sociais." Pode-se dizer que representações sociais são a maneira como os indivíduos de uma determinada sociedade, pertencentes a um determinado grupo social, expressam a sua realidade e a interpretam, dependendo do seu nível de conhecimento, partindo da construção de um saber próprio pautado na sua experiência do cotidiano. Sobre esse prisma é que se lançou luz às representações de amamentação das mães que fizeram parte do presente estudo.

A MDER é uma instituição pública, estadual, situada em Teresina, PI, Brasil, que tem as suas ações de assistência dirigida para a saúde da mulher, da criança e do adolescente. Por ser uma instituição IHAC, suas diretrizes, normas e rotinas estão em conformidade com o disposto no modelo assistencial proposto pela IHAC, que contempla a meta de amamentação exclusiva por quatro a seis a meses.

Com base no pressuposto de que o desmame precoce está relacionado com as dificuldades do modelo assistencial em lidar com os fatores socioculturais que permeiam a amamentação, foram incluídas, no estudo, as mulheres assistidas na MDER que: freqüentaram pelo menos seis consultas durante o pré-natal, tiveram parto a termo, fizeram o acompanhamento regular de seus filhos no serviço de puericultura e ini- 
ciaram o processo de desmame antes do quarto mês de vida do bebê. Somente participaram do estudo as mulheres que tiveram crianças a termo, sem nenhum tipo de intercorrência no parto ou pós-parto. A maioria das crianças encontrava-se em idade inferior a seis meses (92\%), as outras ( $8 \%$ ) estavam no intervalo entre seis e 12 meses.

O número de entrevistadas, 24 mulheres ao todo, definiu-se com base no critério de saturação dos temas pesquisados. Segundo Minayo, 10 o número adequado de entrevistas deve ser entendido como aquele capaz de refletir a totalidade nas suas dimensões.

A participação das mulheres no estudo deu-se de forma voluntária e foram obeservados os dispositivos legais que regulamentam atividades de pesquisa envolvendo seres humanos. 11 Conduziramse as entrevistas com o auxílio de um roteiro temático, tomando o cuidado de não cercear a fala das entrevistadas. No que tange a assistência em amamentação, o roteiro temático contemplou: por que procurou a MDER; como foi o pré-natal, o pré-parto, o puerpério; a alta hospitalar; consultas de seguimento; pontos fortes e pontos fracos; sugestões de melhoria; relação com os profissionais de saúde; a usuária frente as rotinas hospitalares. As entrevistas foram gravadas e transcritas.

A análise das falas das mulheres realizou-se com base na técnica de análise de conteúdo, que consiste em descobrir os núcleos de sentido que fazem parte da comunicação e cuja a presença ou frequência importam em algum significado para os objetivos aos quais nos propomos. Segundo Gomes, 12 esse tipo de metodologia serve principalmente para a verificação de hipóteses ou questões formuladas, como também, para confirmar ou não as afirmações estabelecidas durante o trabalho de campo.

\section{Resultados}

A análise compreensiva possibilitou localizar na fala das entrevistadas dois eixos para discussão: um relacionado à vivência de cada uma delas durante o ciclo gravídico puerperal, e outro, no qual demonstraram suas percepções acerca da assistência recebida durante cada fase, quais sejam: o pré-natal, o parto, o puerpério e as consultas de seguimento.

A seguir serão apresentadas as considerações das mulheres de acordo com cada fase vivenciada na maternidade.

\section{A gravidez}

A gravidez se apresentou como um momento de con- flito, principalmente, pelo fato de não ter sido, na maioria das vezes, fruto de um planejamento prévio: "Ai meu Deus! É bom ter um filho, mas (pausa) é difícil [...] porque o nenen toma muito tempo da gente, mas assim é ótimo!"; "... não foi uma gravidez planejada, não que eu não aceite, que eu aceito"; "... quando você descobre que está grávida, que não está gostando da criança, mas com o tempo você vai gostando, vai aceitando ..."; "No início da minha gravidez foi difícil porque meus pais não queriam aceitar e tal [...] não foi uma gravidez planejada ..." Quando se tratou da mulher adolescente, a gravidez representou, invariavelmente, um grau de transtorno para a família: "... eu engravidei com 16 anos, foi um choque para todo mundo aqui em casa ..."

\section{O parto}

O parto ficou marcado nas mulheres como um momento de sofrimento físico, tomado pelo sentimento de solidão e pela sensação de falta de preparo para vivenciá-lo: "... fiquei triste no momento do parto porque foi uma experiência bem diferente, dolorida né ..."; "...eu chorava, não sei se era de dor ou de medo de ir pra maternidade, eu tinha tanto medo de ficar sozinha ..."

\section{O puerpério}

O puerpério, à semelhança do pré-parto e parto, se encontrou marcado pelos sentimentos de solidão e desamparo das mulheres. A tônica das falas se concentrou na falta de apoio, principalmente em lidar com o recém-nascido, e em especial, com as questões relacionadas a amamentação: "Tinha que ter uma enfermeira ali com a gente, ela falasse - olha quando ele tiver chorando bota ele no peito [...] eu senti mais falta de uma enfermeira ali comigo ou então de um parente meu que tivesse experiência ...".

\section{Consultas de seguimento}

A experiência da amamentação se revelou como um momento conflituoso para as mulheres, no qual as orientações recebidas na maternidade nem sempre correspondiam à prática vivida por elas, tornando essa fase repleta de medo e insegurança: "Elas orientam a gente, tiram as dúvidas, porque a gente tem muita dúvida, principalmente depois que a criança nasce né ..."; "Eu pensava que ela ia brigar comigo, porque todas as pessoas lá, tavam perto de mim, lá na maternidade, falavam: 'ela vai dar bronca em $t i$ porque tu tá dando leite'..."

No que diz respeito à assistência em amamen- 
tação, a recebida pelas mulheres durante toda a trajetória do pré-natal até as consultas de seguimento, pode-se perceber que a mulher, invariavelmente, durante todo o tempo, fez avaliações acerca da assistência recebida. Sob esse enfoque, alguns temas apareceram de forma bem enfática a partir de suas falas. Pode-se destacar entre eles: a assistência no pré-natal e no parto; as rotinas hospitalares, as informações recebidas; o discurso dos profissionais; normas existentes.

\section{Assistência no pré-natal e parto}

A atenção dispensada pela equipe de saúde no prénatal e parto foi muito valorizada nas falas. Muitas mulheres se dirigiram de forma bem enfática à figura do médico, que, segundo elas, deveria dar mais informações sobre a gravidez, o parto e a amamentação, além de realizar o exame das mamas de forma rotineira e oferecer um apoio efetivo, pois assim estaria contribuindo para que a mulher se tornasse mais segura frente ao ciclo gravídico-puerperal e para a consecução da amamentação: "... no pré-natal, tem muitas atendentes que são boas, só que tem outras que são muito ignorantes. As vezes elas vêm de casa mal humoradas e terminam vindo descontar na gente ..."; "Eu tive mais ou menos sete consultas, o meu médico nunca falou sobre amamentação, falou de jeito nenhum ...";"Não dessa época do natal, só mesmo a palestra, depois eu não procurei saber sobre amamentação não, só depois que eu tive a criança [...] não, eu não vou me preocupar saber é ... sobre aleitamento porque eu não tou precisando agora".; "Não gostei mais ainda do médico que tava fazendo o meu pré-natal porque ele nunca falou sobre amamentação [...] ele nunca examinou minhas mamas". O discurso das mulheres revela por um lado a preocupação por não terem recebido nenhuma informação sobre o assunto, sobretudo dos médicos, por outro lado, percebe-se a falta de preocupação em tratar desse tema nessa fase.

Com relação ao parto, a banalização da dor por parte da equipe, durante o trabalho de parto, mereceu destaque na fala das entrevistadas: "... acho que virar pra você e mandar você calar a boca, isso aí sinceramente fiquei com ódio disso aí ..."

\section{As rotinas hospitalares}

As rotinas hospitalares adotadas na instituição, em atenção ao cumprimento dos 10 passos para o sucesso da amamentação, preconizadas pela IHAC, se configuraram em objeto de crítica por parte das entrevistadas: "... eu não gosto muito do negócio de lá
... de lá, por exemplo, o bebê nasce, ele joga ali na mãe [...] Eu fiquei abandonada"; "... queria assistir a palestra porque eu achava muito interessante, não sabia de nada do que ela tava falando ali ..."; "... a gente quer ir embora logo [...] a gente querendo ir embora e elas conversando."

\section{Informações recebidas}

As informações repassadas pelos serviços de saúde são constantemente avaliadas pelas mulheres, que as confrontam com suas próprias vivências e, dessa maneira, questionam os novos valores que lhe são ofertados: "... ela disse que não existe leite fraco não, a gente pensa né que existe ..."; "Elas dizem que .. .é da cabeça da gente, é imaginação, que a gente tem leite pra amamentar...".

\section{Discurso dos profissionais}

O distanciamento entre as percepções da mulher e as proposições do modelo assistencial se fizeram evidentes nas falas, revelando um verdadeiro descompasso entre o discurso dos profissionais e a prática das mulheres: "... a gente sempre faz diferente de lá, elas falam sempre uma coisa, aconselham aquilo que é bom, é melhor, é o certo [...] a gente acha dificuldade [...] aî é o jeito a gente fazer as coisas diferentes...".

\section{Normas existentes}

A distância que se estabelece entre as proposições contempladas pelas normas a favor da amamentação e a prática das mulheres que iniciaram o desmame antes do quarto mês, também se fez perceber em relação ao uso de bicos e chupetas: "... ele chorou e aí eu fiquei preocupada [...] até minha mãe aconselhou a dar chupeta ..."; "... eu sei que é ruim dar bico, mas eu dou [...] a gente dá bico que é pra ficar mais calmo ...". Apesar dos constantes alertas às mães sobre o efeito nocivo dos bicos artificiais e da rigidez das rotinas hospitalares, que impedem definitivamente essa prática durante a internação, não foi possível observar o eco desejado na fase pós-alta. Uma vez em casa, as mães se mostraram favoráveis ao uso de mamadeiras, por entenderem que esses recursos aliviam-na da dependência de criança, além de se configurar como uma alternativa prática, capaz de permitir que ela compatibilize o ser mãe com todas as demais atribuições e incumbências que lhe dizem respeito. 


\section{Discussão}

A busca acerca da compreensão das mulheres sobre a assistência recebida no tocante à amamentação revelou também como foi a vivência de cada uma delas frente ao ciclo gravídico-puerperal, demonstrando que cada uma das etapas vencidas representou momentos de solidão e de desamparo.

A gravidez, nesse contexto, fez aflorar um sentimento ambíguo e ao mesmo tempo contraditório, pelas mudanças que ocasionam na vida das mulheres, e também, por ter se revelado, na maioria dos relatos, não planejada. Almeida e Couto, 13 comentam que a gravidez e o puerpério podem gerar temores e ansiedade para a mulher. Para Silva, ${ }^{14}$ esse fato decorre da percepção de algo novo e inesperado na vida, com o qual a mulher ainda não aprendeu a lidar. Existem muitas razões para as mulheres engravidarem, sendo o amor a principal razão para o casamento, e um filho é visto como o fruto deste amor. Porém, muitas gravidezes não são desejadas nem planejadas, sendo aceitas somente após um tempo. Algumas sequer são aceitas. 6

Participaram do estudo seis adolescentes. Nesses casos, os sentimentos conflituosos se prestaram para ampliar a vulnerabilidade emocional da mulher, tanto na gestação, como durante todo o processo de amamentação. A percepção dos pais se configurou no elemento desencadeador de tais sentimentos, pois muitas vezes a adolescente não conta com o apoio do pai da criança e/ou da própria família. 15

Com relação ao momento do parto, as parturientes submetidas à dor e ao stress, em ambientes pouco receptivos, vivenciaram a experiência do parto de forma sofrida e traumática. Além da necessária preparação para o parto que deve ocorrer durante o pré-natal, com ênfase em ações psico-profiláticas, alguns autores denotam a importância da presença de uma pessoa ao lado da mulher, com a função exclusiva de acompanhá-la no período peripartal, a semelhança das "doulas" que existem em algumas culturas. ${ }^{16}$ Além disso, é referida a importância da participação do pai e familiares durante o parto e o contato precoce dos pais com seus filhos. ${ }^{17}$

O puerpério, tal qual o parto, mostrou ser um momento difícil, especialmente pela falta de apoio para cuidar da criança. Segundo Vinha, 18 o puerpério representa uma importante fase de adaptação, na qual a mulher necessita de apoio, ajuda e certos cuidados, face aos sentimentos de insegurança, medo, conflitos e ansiedades que vivencia. Os sentimentos maternos no pós-parto são, sem dúvida, grandes influenciadores do que irá ocorrer em relação à amamentação.

Com relação à assistência recebida pelas mu- lheres, merecem destaque o pré-natal e o momento do parto. O fato de a gestação representar um dos momentos de maior vulnerabilidade na vida da mulher, apesar de não constituir novidade deveria se configurar num dos principais objetos de preocupação do serviço. Contudo, a invés do serviço se mostrar aparelhado para lidar adequadamente com as questões da gestante, compreendendo-a, amparando-a, foi observado o inverso. As gestantes, preocupadas em garantir o seu atendimento, se recolheram à condição de pacientes, e como tal, se lançaram a compreender aqueles que deveriam compreendê-las.

Em relação à dor, muito referenciada pelas mulheres na hora do parto, é relatada no estudo de Hotmsky et al., ${ }^{19}$ como um processo de naturalização do sofrimento ligado à maneira como se dá a construção social de gênero prevalente entre as camadas populares brasileiras. Segundo a autora, a relação entre os profissionais de saúde e pacientes, se dá, muitas vezes, através da desconfiança, desrespeito e conflito, especialmente quando se trata daqueles pertencentes a camadas socioeconômicas desfavorecidas.

As mulheres, com base na experiência vivida durante o transcurso da gravidez, parto e puerpério dentro da maternidade, podem avaliar constantemente a assistência recebida. Nesse aspecto, merecem destaque as normas adotadas na instituição para apoiar a amamentação. $\mathrm{O}$ cumprimento das normas por si, tal qual foram delineadas originalmente, não se mostrou universalmente eficaz para o estabelecimento de amamentação. As mulheres, clientes e não apenas pacientes, denunciam em sua falas a falta de um suporte adequado no serviço, capaz de responder a seus anseios e necessidades individuais, construídas a partir dos referenciais que compõem as suas histórias de vida. Essa constatação, mais do que um alerta, representa uma oportunidade para reformular as estruturas assistenciais destinadas a promover suporte à mulher que precisa vencer as dificuldades iniciais para o estabelecimento de amamentação.

Um outro ponto avaliado pelas mulheres foram as informações repassadas pelos profissionais de saúde. Os valores que compõem a matriz vivencial da mulher, na maioria das vezes construídos a partir do senso comum, tendem a sobrepor aos novos conhecimentos que lhe são ofertados através dos serviços de saúde, particularmente, no que tange a amamentação. A figura do leite fraco ou do pouco leite é uma das mais evidentes constatações dessa tendência, uma vez que desde o início do século XVIII, por mais que a medicina tenha oferecido argumentos cientificamente embasados à sociedade, no sentido de comprovar que todas as mulheres são capazes de produzir leite em qualidade e quantidade suficiente 
para propiciar o crescimento adequado dos seus filhos, um número significativo de mulheres continuava a insistir que isso não é possível. ${ }^{5}$

A bipolarização que se estabelece entre o senso comum e o saber científico em torno do leite fraco representa uma dificuldade histórica do profissional de saúde em lidar com as questões subjetivas e singulares da mulher. Os programas de saúde tendem a buscar a solução para os problemas da nutriz através da dimensão biológica, adotando práticas que estimulam a glândula mamária e evocando sempre o instinto materno como algo inato e próprio da espécie humana, que por sua vez compõe o universo dos mamíferos. O grande equívoco que se comete nesse tipo de abordagem é o de considerar apenas os determinantes biológicos, deixando de lado os condicionantes sociais que permeiam a amamentação e que, inclusive, tendem a se sobrepor aos determinantes biológicos. 20

Por fim, há de se destacar que o hiato entre o discurso do profissional de saúde e a prática vivenciada pelas mulheres foi o elemento de mais relevo nas falas, funcionando como uma espécie de fio condutor que uniu os diferentes argumentos e alegações no decorrer de todas as entrevistas. A informação não se mostrou eficiente em si mesma, e a questão que surge diz respeito ao modelo assistencial vigente, em considerá-la como atividade finalística. Assim, pode-se concluir que não basta informar; o trabalho deve ser direcionado no sentido de possibilitar a introjeção de um novo valor cultural, um conjunto de valores que componha a bagagem de vida da mulher. Nessa perspectiva, o atual modelo assistencial em amamentação não se revelou capaz de lidar com as condições concretas de vida das nutrizes, o que termina por impedí-las de amamentarem.

\section{Considerações finais}

O conhecimento da experiência vivida pelas mulheres a partir da assistência recebida na MDER, durante o ciclo gravídico-puerperal, possibilitou ampliar a compreensão acerca da percepção do assistir em amamentação, sob a ótica da cliente. Além disso, foi possível evidenciar questões ligadas ao parto e ao puerpério, que refletem algumas necessidades de mudança na forma como se estrutura o atendimento.

As mulheres vivenciaram a gestação e o parto como experiências repletas de sentimentos ambíguos e ao mesmo tempo contraditórios. A ansiedade, o medo, a solidão e o desamparo acompanharam a mulher durante todo o seu percurso na instituição, desde o momento da descoberta da gravidez até a alta hospitalar.

A falta de preparo para o momento do parto, aliado à dificuldade da maternidade em lidar com a condução dessa etapa, tornou essa experiência extremamente dolorosa e traumatizante. Além disso, há de se destacar a necessidade do desenvolvimento de um trabalho dirigido à mulher, no sentido de prepará-la para o parto, puerpério e amamentação, contemplando as questões subjetivas da mulher, numa dimensão psico-profilática. Nesse sentido, o acompanhamento da mulher, a partir do pré-parto, se configura como uma medida importante e que deve ser implantada, em resposta a um dos principais problemas que elas tiveram de vencer: a solidão.

As principais falhas na atenção pré-natal, em relação ao preparo para a futura amamentação, se relacionaram com a pouca efetividade na comunicação estabelecida entre as gestantes e os profissionais de saúde, sobretudo com os médicos. Sob este enfoque, a principal questão levantada pelas mulheres se encerra na necessidade de serem ouvidas.

A solidão e o desamparo, acrescido à falta de experiência de lidar com o bebê, principalmente no que diz respeito à iniciação e ao estabelecimento da amamentação, foi a tônica da fala das mulheres em relação ao puerpério. Ao que parece, a instituição não oferece um suporte adequado às necessidades da mulher, e quando o faz, se limita as questões relativas ao manejo da lactação, através de uma abordagem predominantemente biologicista. Ao contrário, os relatos evidenciam a necessidade de apoio, no sentido de haver alguém capaz de escutar as suas angústias e diminuir as ansiedades geradas pelo comportamento do bebê, que para elas representa algo novo e desconhecido.

A atuação dos profissionais de saúde deu-se de forma descompassada, revelando o grande hiato que se estabelece entre o discurso proferido por eles e a prática que compõe o cotidiano da mulher. A assistência em amamentação se configurou como um atendimento impessoal, apesar de todas as proposições normativas, o que visivelmente impossibilitou operar com as questões subjetivas que permeiam a gestação, o parto, o puerpério e a amamentação, culminando com a prática do desmame antes do quarto mês de vida do bebê.

De um lado as mulheres reclamam a falta de apoio e do outro os profissionais percebem e reconhecem os anseios da mulher, mas definitivamente não são capazes de romper com o modelo em vigor. Há de se buscar um caminho que possibilite compatibilizar os determinantes biológicos e os condicionantes sociais que permeiam a amamentação, entendendo-a como uma categoria híbrida, com elementos definidos tanto pela natureza, como pela cultura, 5 sem supervalorizar uma dimensão em detrimento da outra. 


\section{Referências}

1. Muller M. O matador de bebês. Campinas: Cemicamp; 1981. 2. OMS (Organização Mundial de Saúde), UNICEF (Fundo das Nações Unidas para a Infância). Proteção, promoção, apoio ao aleitamento materno: o papel especial dos serviços maternos infantis. Genebra: A Organização; 1989.

3. OMS (Organização Mundial de Saúde), UNICEF (Fundo das Nações Unidas para a Infância). Manual técnico: manejo e promoção do aleitamento materno num Hospital Amigo da Criança. Curso de 18 horas para equipes de maternidade. Genebra: A Organização; 1993.

4. UNICEF (Fundo das Nações Unidas para a Infância). Situação mundial da infância: 1998. Brasília (DF): O Fundo; 1998.

5. Almeida JAG. Amamentação: um híbrido da natureza - cultura. Rio de Janeiro: Fundação Oswaldo Cruz; 1999.

6. Lana APB. O livro de estímulo à amamentação: uma visão biológica, fisiológica e psicológica-comportamental da amamentação. Belo Horizonte: Atheneu; 2001.

7. Situação da Iniciativa Hospital Amigo da Criança no Brasil. Disponível em: http:://www.aleitamento.org.br/ihac/situaihac.htm. [26 Maio 2003].

8. Minayo MCS. Ciência, técnica e arte: o desafio da pesquisa social. In: Minayo MCS, organizadora. Pesquisa social: teoria, método e criatividade. Petrópolis: Vozes; 1994.

9. Minayo MCS. O conceito de representações sociais dentro da sociologia clássica. In: Jochelovichs, Guareshi P, organizadores. Texto em representações sociais. Rio de Janeiro: Vozes; 1994. p. 89-111.

10. Minayo MCS. Desafio do conhecimento: pesquisa qualitativa em saúde. São Paulo: Hucitec; 1992.

11. Ministério da Saúde. Fundação Oswaldo Cruz. Diretrizes e normas regulamentadoras de pesquisa envolvendo seres humanos: resolução 196/96 do Conselho Nacional de Saúde. Rio de Janeiro: O Ministério; 1998.
12. Gomes R. A análise de dados em pesquisa qualitativa. In: Minayo MCS, organizadora. Pesquisa social: teoria, método e criatividade. Petrópolis: Vozes; 1994. p. 67-80.

13. Almeida JAG, Couto LS. Amamentação: um dilema entre amamentar e promover. In: Anais do I Congresso do Cone Sul de Aleitamento Materno [CD-ROM].

14. Silva IA. Amamentar: uma questão de assumir riscos ou garantir benefícios. São Paulo: Robe; 1997.

15. Gama SNG, Szarcwald CL, Leal MC. Experiência de gravidez na adolescência, fatores associados e resultados perinatais entre puérperas de baixa renda. Cad Saúde Pública 2002; 18: 153-61.

16. Helsing E, King FS. Breast-feeding in practice: a manual for health workers. Nairobi Kuala Lumpur: British Library; 1985.

17. Silva AMR, Andrade SM, Thomson Z. Opiniões de mães de crianças que morreram no primeiro ano de vida no município de Londrina, Paraná, Brasil. Cad Saúde Pública 2002; 18: 1295-302.

18. Vinha VHP. O livro da amamentação. São Paulo: CLR Brasileiro; 1999.

19. Hotmsky SN, Ruther D, Venâncio SI, Bógus CM, Miranda MM. O parto como eu vejo ... ou como eu desejo? Expectativa de gestantes, usuárias do SUS, acerca do parto e da assistência obstétrica. Cad Saúde Pública 2002; 18 : 1303-11.

20. Almeida JAG. Leite fraco: um problema da mama ou da cultura. Masto Magazine 1998; 2: 2.

Recebido em 3 de março de 2003

Versão final reapresentada em 16 de julho de 2003

Aprovado em 13 de agosto de 2003 